\title{
Ni-Catalyzed Aryl Sulfide Synthesis through an Aryl Exchange Reaction
}

\author{
Ryota Isshiki, ${ }^{a}$ Miki B. Kurosawa, ${ }^{a}$ Kei Muto, ${ }^{b}$ and Junichiro Yamaguchi ${ }^{*{ }^{a}}$ \\ ${ }^{a}$ Department of Applied Chemistry, Waseda University, 513 Wasedatsurumakicho, Shinjuku, Tokyo 162-0041, Japan. \\ ${ }^{b}$ Waseda Institute for Advanced Study, Waseda University, 513 Wasedatsurumakicho, Shinjuku, Tokyo 162-0041, Japan
}

\begin{abstract}
A Ni-catalyzed aryl sulfide synthesis through an aryl exchange reaction between aryl sulfides and a variety of aryl electrophiles was developed. By using 2-pyridyl sulfide as a sulfide donor, this reaction achieved the synthesis of aryl sulfides without using odorous and toxic thiols. The use of a Ni/dcypt catalyst capable of cleaving and forming aryl-S bonds was important for the aryl exchange reaction between 2pyridyl sulfides and aryl electrophiles, which include aromatic esters, arenol derivatives, and aryl halides. Mechanistic studies revealed that $\mathrm{Ni} /$ dcypt can simultaneously undergo oxidative additions of aryl sulfides and aromatic esters, followed by ligand exchange between the generated aryl-Ni-SR and aryl-Ni-OAr species to furnish aryl exchanged compounds.
\end{abstract}

Aryl sulfide is an important chemical motif that is widely seen in biologically active compounds, as well as in chemical materials. ${ }^{1}$ Due to this importance, there has been interest among chemists to expand the methodology toward the synthesis of aryl sulfides. Conventionally, metal-catalyzed $\mathrm{C}-\mathrm{S}$ bond formations of aryl electrophiles with thiols has been utilized (Figure 1A) ${ }^{2,3}$ Contrary to the high reliability of this method, the use of thiols is often shunned because of their odor and toxicity. The reaction of aryl halides with disulfides, ${ }^{4}$ and decarbonylation reaction of thioesters have been developed as alternatives. ${ }^{5}$ Recently, a reaction using alkyl sulfides as a sulfide source has emerged using palladium catalysis under strongly basic conditions. ${ }^{6}$ Despite these progresses in this area, the development of $\mathrm{C}-\mathrm{S}$ bond formation without thiols is still a topic in its infancy. ${ }^{?}$

Meanwhile, transition metal-catalyzed aryl exchange reactions between two different aryl electrophiles have gained attention in recent years. ${ }^{8,9}$ This type of transformation is not only conceptually interesting but also synthetically valuable because it is possible to avoid the use of nucleophilic counterparts which often triggers poor functional group tolerance and catalyst deactivation. As a pioneering work, Morandi and Arndtsen independently reported a Pd-catalyzed aryl exchange reaction between aryl iodides and aroyl chlorides (Figure 1B). ${ }^{10}$ Commonly, the development of these reactions requires a high level of design. It is important to choose and/or develop an appropriate metal catalyst enabling both the cleavage and formation of two distinct chemical bonds. Another consideration is the design of a set of substrates to control the equilibrium of the reaction.

In related work, our group developed a Ni-catalyzed aryl exchange reaction between aryl halides and aromatic esters (Figure 1B). ${ }^{11}$ The key for this reaction was the high bond-cleaving ability of $\mathrm{Ni} / \mathrm{dcypt}$ catalyst, which also allowed the reaction of challenging arenol derivatives instead of aryl halides. ${ }^{12}$ However, this reaction afforded only aromatic esters as a product, not aryl halides and arenols. We assumed that this is due to the difficulty of reductive elimination of $\mathrm{C}-\mathrm{X}$ bonds from the $\mathrm{Ar}-\mathrm{Ni} / \mathrm{dcypt}-\mathrm{X}$ intermediate $(\mathrm{X}=$ halogen and OR). Because it is known that $\mathrm{C}-\mathrm{S}$ bond reductive elimination is a relatively facile process in metal catalysis, ${ }^{13}$ we envisioned that aryl sulfide synthesis by a catalytic aryl exchange reaction would be reasonable and possible. Herein, we report a new aryl sulfide synthesis by means of a $\mathrm{Ni} /$ dcypt-catalyzed aryl exchange between aryl sulfides and aromatic esters (Figure 1C). Moreover, this nickel catalysis was revealed to be viable for various aryl electrophiles such as aryl halides and arenols other than aromatic esters. During the preparation of this manuscript, Morandi reported a similar aryl sulfide synthesis using an aryl exchange reaction between aryl sulfides with aryl nitriles. ${ }^{14}$

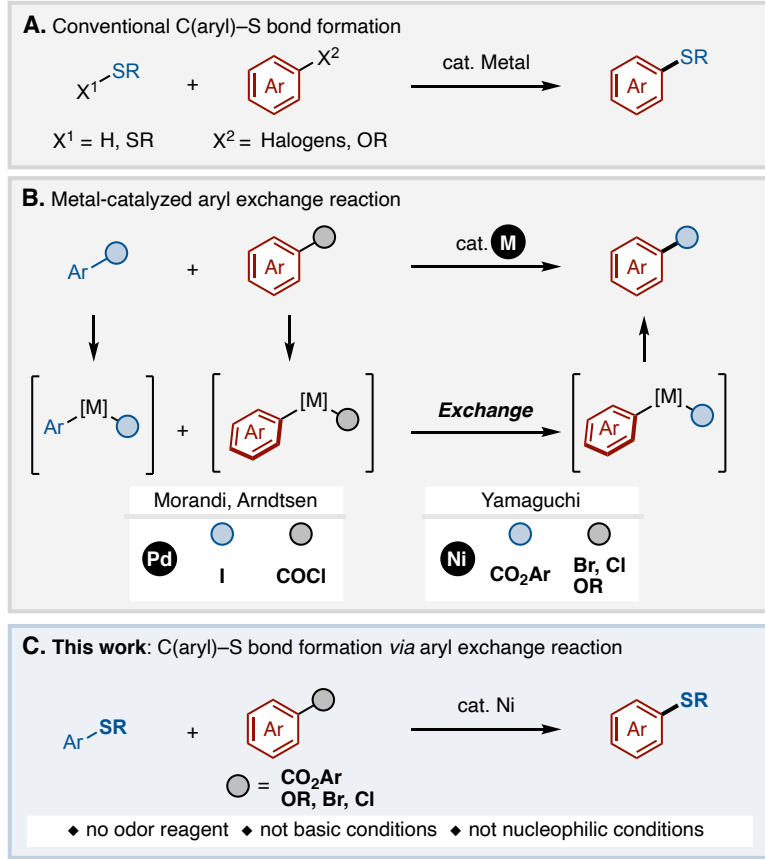


Figure 1. (A) Conventional catalytic C-S bond formations. (B) Catalytic aryl exchange reactions. (C) Ni-Catalyzed aryl sulfide synthesis via aryl exchange reaction.

To initiate the study, 4-tolyl sulfide $\mathbf{1 A}$ and 4-phenylbenzoate $\mathbf{2 a}$ were reacted under the conditions for our previous aryl exchange reaction $\left(\mathrm{Ni}(\mathrm{OAc})_{2} /\right.$ dcypt catalyst, $\mathrm{Zn}$, and $\left.\mathrm{Na}_{3} \mathrm{PO}_{4}\right)$ (Table 1$)$. To our delight, the desired aryl sulfide 4Aa was obtained in $43 \%$ yield along with $16 \%$ yield of aromatic ester 5 (Table 1, entry 1 ). In this case, phenyl propyl sulfide was also generated as a major byproduct, which is derived from the phenol moiety on 2a through an undesired $\mathrm{C}(\operatorname{aryl})-\mathrm{O}$ bond cleavage (see the Supporting Information for details). ${ }^{11,12 a-12 d}$ In order to suppress this undesired pathway, we utilized tolyl ester $3 \mathrm{a}$ with the expectation that the ortho-methyl group can block the $\mathrm{C}(\operatorname{aryl})-\mathrm{O}$ bond oxidative addition (Table 1 , entry 2). As expected, the yield of 4Aa was improved to $58 \%$, and significantly decreased the formation of phenyl propyl sulfide. A change from $\mathrm{Ni}(\mathrm{OAc})_{2}$ to $\mathrm{Ni}(\mathrm{cod})_{2}$ decreased the yields of $4 \mathrm{Aa}$ and 5 (Table 1, entry 3). Hypothesizing that the conditions using $\mathrm{Ni}(\mathrm{OAc})_{2}$ and $\mathrm{Zn}$ produces $\mathrm{Zn}(\mathrm{OAc})_{2}$ which might promote this reaction, we added a semi-catalytic amount of $\mathrm{Zn}(\mathrm{OAc})_{2}$ into the reaction with $\mathrm{Ni}(\mathrm{cod})_{2}$. As expected, we obtained a comparable result with the conditions using $\mathrm{Ni}(\mathrm{OAc})_{2}$ (Table 1 , entries 2 and 4). Moreover, the addition of $\mathrm{Zn}(\mathrm{OAc})_{2}$ to the conditions using $\mathrm{Ni}(\mathrm{OAc})_{2}$ improved the yield of $3 \mathrm{Aa}$ to $80 \%$ whereas the yield of 5 remained same (Table 1, entry 5). Removing $\mathrm{Na}_{3} \mathrm{PO}_{4}$ from these conditions decreased the yields of 4Aa and 5 (Table 1, entries 6 and 7). It was revealed that Pd/dcypt catalyst can also work without $\mathrm{Zn}(\mathrm{OAc})_{2}$ to give $4 \mathrm{Aa}$ and 5 albeit in lower yields (Table 1, entry 8 ). Finally, it was found that the choice of ligand was crucial. Our dcypt ligand effectively worked well, yet other diphosphines and monophosphines were totally ineffective (Table 1, entries 9-12). With these studies, $\mathrm{Ni}(\mathrm{OAc})_{2} / \mathrm{dcypt} / \mathrm{Zn} / \mathrm{Zn}(\mathrm{OAc})_{2}$ catalysis was identified as our optimized conditions. Of note, a similar $\mathrm{Ni} / \mathrm{Zn}$ catalysis was often employed for reductive biaryl coupling of two aryl electrophiles, but such a biaryl formation did not occur in this case. ${ }^{15}$

Table 1. Optimization of reaction conditions
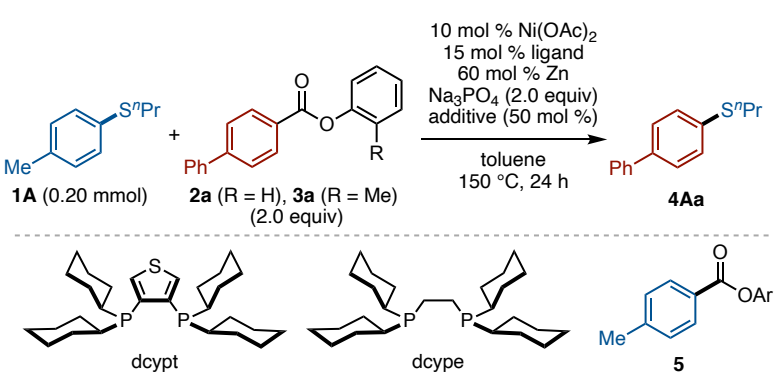

$\begin{array}{llllll}\text { entry } & \mathrm{R} & \text { ligand } & \text { additive } & \begin{array}{l}\text { Yield of } \\ \mathbf{4 a} / \%^{a}\end{array} & \begin{array}{l}\text { Yield of } \\ \mathbf{5} / \%^{a}\end{array} \\ 1 & \mathrm{H} & \mathrm{dcypt} & & 43 & 16 \\ 2 & \mathrm{Me} & \mathrm{dcypt} & & 58 & 23 \\ 3^{b} & \mathrm{Me} & \mathrm{dcypt} & & 24 & 17 \\ 4^{b} & \mathrm{Me} & \mathrm{dcypt} & \mathrm{Zn}(\mathrm{OAc})_{2} & 58 & 24 \\ 5 & \mathrm{Me} & \mathrm{dcypt} & \mathrm{Zn}(\mathrm{OAc})_{2} & 80(80)^{e} & 24 \\ 6^{c} & \mathrm{Me} & \mathrm{dcypt} & & 51 & 19 \\ 7^{c} & \mathrm{Me} & \mathrm{dcypt} & \mathrm{Zn}(\mathrm{OAc})_{2} & 71 & 16 \\ 8^{d} & \mathrm{Me} & \mathrm{dcypt} & & 33 & 5\end{array}$

$\begin{array}{llllll}9 & \mathrm{Me} & \text { dcype } & \mathrm{Zn}(\mathrm{OAc})_{2} & 24 & \text { trace } \\ 10 & \mathrm{Me} & \text { dppe } & \mathrm{Zn}(\mathrm{OAc})_{2} & 7 & 0 \\ 11 & \mathrm{Me} & \text { Xantphos } & \mathrm{Zn}(\mathrm{OAc})_{2} & 0 & 0 \\ 12 & \mathrm{Me} & \mathrm{P}^{n} \mathrm{Bu}_{3} & \mathrm{Zn}(\mathrm{OAc})_{2} & 0 & 0\end{array}$

Conditions: $1 \mathrm{~A}(0.20 \mathrm{mmol}), \mathbf{2}$ (2.0 equiv), $\mathrm{Ni}(\mathrm{OAc})_{2}(10 \mathrm{~mol} \%)$, ligand (bidentate: $15 \mathrm{~mol} \%$, monodentate: $30 \mathrm{~mol} \%), \mathrm{Na}_{3} \mathrm{PO}_{4}(2.0$ equiv), toluene $(0.80 \mathrm{~mL}), 150{ }^{\circ} \mathrm{C}, 24 \mathrm{~h} .{ }^{a} \mathrm{NMR}$ yield. ${ }^{b} \mathrm{Ni}(\mathrm{cod})_{2}$ instead of $\mathrm{Ni}(\mathrm{OAc})_{2 .}{ }^{c}$ Without $\mathrm{Na}_{3} \mathrm{PO}_{4} .{ }^{d} \mathrm{Pd}(\mathrm{OAc})_{2}$ instead of $\mathrm{Ni}(\mathrm{OAc})_{2 .}{ }^{e}$ Isolated yield.

Although we established the optimized conditions, the two following questions arose. Can two distinct oxidative additions to the same Ni/dcypt catalyst can occur? Can the two generated nickel complexes engage in the exchange reaction? To answer these questions, we next carried out several mechanistic studies. We first confirmed the oxidative addition reaction of aryl sulfide $\mathbf{6 A}$ to $\mathrm{Ni}(\operatorname{cod}) /$ dcypt complex (Figure $2 \mathrm{~A}) .{ }^{16}$ The reaction of equimolar $\mathrm{Ni}(\operatorname{cod})_{2}$, dcypt, and aryl sulfide $6 \mathrm{~A}\left(2.0\right.$ equiv) in toluene at $80^{\circ} \mathrm{C}$ smoothly furnished oxidative addition complex 7 in $83 \%$ yield. The structure of 7 was unambiguously confirmed by $\mathrm{X}$-ray crystallographic analysis. Next, we attempted a double oxidative addition of aryl sulfide $6 \mathbf{A}$ and aromatic ester $3 \mathbf{b}$ to $\mathrm{Ni}(\operatorname{cod})_{2} / \mathrm{dcypt}$ at $80^{\circ} \mathrm{C}$, and the time course plot is shown in Figure $2 \mathrm{~B}$ (for the details, see the SI). It was observed that $\mathbf{6 A}$ undergoes a much faster oxidative addition than $\mathbf{3 b}$. Interestingly, during this reaction, the amount of 8 and 9 constantly increased, and that of 7 and $\mathrm{Ni}(\operatorname{cod}) / \mathrm{dcypt}$ decreased, giving yields of 8 and 9 of $49 \%$ after $42 \mathrm{~h}$. This result indicates the reversibility of the $\mathrm{C}-\mathrm{S}$ bond's oxidative addition and reductive elimination. This reversibility was directly confirmed by the reaction between 7 and aromatic ester $3 \mathbf{b}$ in toluene at $90{ }^{\circ} \mathrm{C}$ giving nickel complexes 8 and 9 in $11 \%$ and $12 \%$ yield, respectively (Figure 2C, see the SI for details). With these studies, we concluded that one of the key aspects of these two simultaneous oxidative additions would be the reversible oxidative addition and reductive elimination of $\mathrm{C}-\mathrm{S}$ bonds. This reversibility would allow for aromatic esters to undergo oxidative additions to the $\mathrm{Ni}(0)$ species albeit in a slow reaction rate. Finally, the reaction of 7 and 8 furnished $4 \mathbf{A b}$ (59\% yield) along with $\mathbf{6 A}$, showing that an exchange reaction between two nickel intermediates is possible (Figure 2D).

Our next interest was to clarify why this reaction provides aryl sulfide 4 as a major product and not aromatic esters. We assumed that the elucidation of the role of $\mathrm{Zn} / \mathrm{Zn}(\mathrm{OAc})_{2}$ might give insights on this question. Thus, aryl exchange reaction between $6 \mathbf{A}$ and $\mathbf{3 b}$ in the presence and absence of $\mathrm{Zn} / \mathrm{Zn}(\mathrm{OAc})_{2}$ was performed by using three different nickel complexes 7,8 , and $9(30 \mathrm{~mol} \%)$ in toluene at $150^{\circ} \mathrm{C}$ (Figure 2E). Without $\mathrm{Zn} / \mathrm{Zn}(\mathrm{OAc})_{2}$, nickel complexes 7 and 9 delivered $4 \mathrm{Ab}$ in $21 \%$ and $36 \%$, respectively. However, 8 gave only $8 \%$ yield of $4 \mathrm{Ab}$. By the addition of $\mathrm{Zn}$ and $\mathrm{Zn}(\mathrm{OAc})_{2}$ into these reactions, the yield of $4 \mathrm{Ab}$ was improved to over $40 \%$ yield in all cases. Judging from these results, we postulated that a $\mathrm{Ni}$-arenoxo complex like 8 would be a resting-state intermediate. To gain further insight on the effect of $\mathrm{Zn}$ and $\mathrm{Zn}(\mathrm{OAc})_{2}$ particularly on the aryl$\mathrm{Ni}$-arenoxo complex, the reaction of aromatic ester $3 \mathrm{c}$ with $\mathrm{Ni}(\operatorname{cod})_{2} /$ dcypt catalyst was performed (Figure $2 \mathrm{~F}$, entry 1 ). As a result, we obtained arene $\mathbf{1 0}$ in $8 \%$ yield, which was thought as a decomposed compound from the aryl-Ni-arenoxo species. Furthermore, the formation of $\mathbf{1 0}$ was accelerated only when both $\mathrm{Zn}$ and $\mathrm{Zn}(\mathrm{OAc})_{2}$ were used (Figure 2F, entries 2-4). Thus, the main role of $\mathrm{Zn}$ and $\mathrm{Zn}(\mathrm{OAc})_{2}$ in this catalysis is the induction of 
reductive decomposition of the aryl-Ni-arenoxo complex to regenerate the $\mathrm{Ni}(0)$ species. However, the $\mathrm{H}$ atom source and detailed action of these zinc reagents were still unclear.

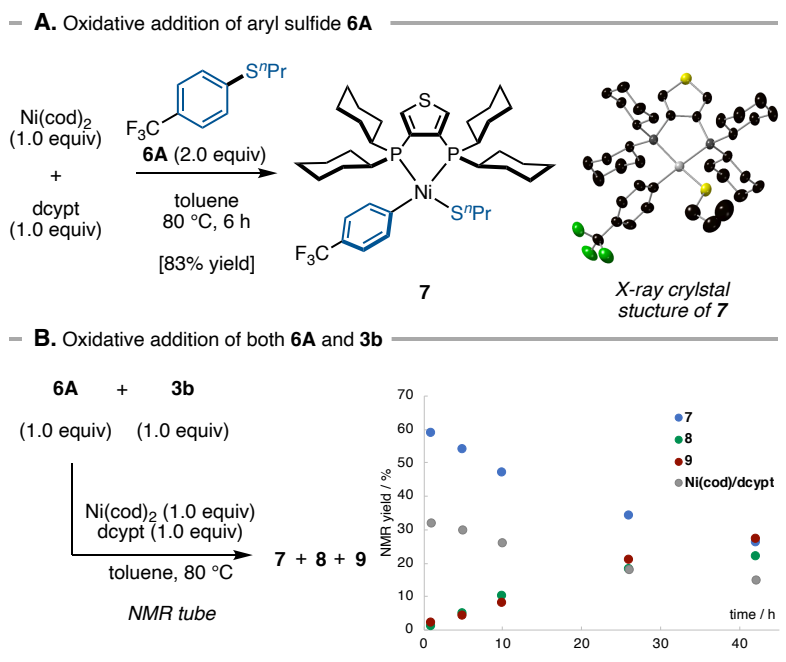

- C. Reaction of $\mathbf{7}$ with $\mathbf{3 b}$

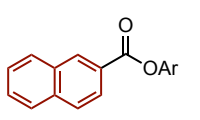
3b $($ Ar $=o$-tolyl $)$
(1.0 equiv)

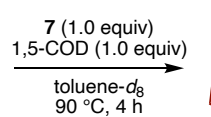

NMR tube

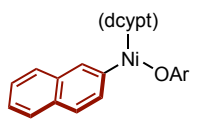

8: $11 \%$ (dcypt)
1
$+\mathrm{OC}^{-\mathrm{Ni}}-\mathrm{CO}$

9: $12 \%$
D. Aryl exchange between $\mathbf{7}$ and 8<smiles>C[Se]N([Ge]C(=O)c1ccccc1)c1ccc(C(F)(F)F)cc1</smiles><smiles>[O-]c1cc2ccccc2cc1N(O[Na])O[Na]</smiles>

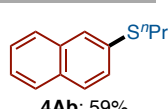

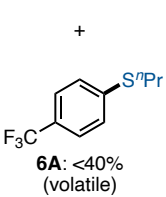

- E. Reaction of $6 \mathrm{~A}$ and $\mathbf{3 b}$ catalyzed by complexes $\mathbf{7 , 8}$, or 9

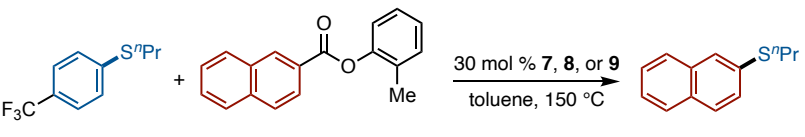

$6 A(0.10 \mathrm{mmol}) \quad 3 b(2.0$ equiv $)$

$4 \mathrm{Ab}$

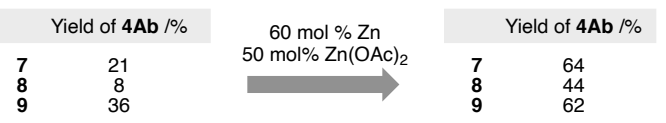

- F. Effect of $\mathrm{Zn}(\mathrm{OAc})_{2}$
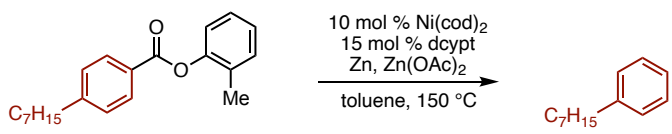

$3 c(0.20 \mathrm{mmol})$

10

entry $\mathrm{Zn}$ (equiv) $\mathrm{Zn}(\mathrm{OAc})_{2}$ (equiv) Yield of $\mathbf{1 0} \% \quad$ Recovery of $\mathbf{3 c} / \%$

$\begin{array}{ccccc}1 & 0 & 0 & 8 & 82 \\ 2 & 1.0 & 0 & 15 & 85 \\ 3 & 0 & 1.0 & 22 & 58 \\ 4 & 1.0 & 1.0 & 60 & 12\end{array}$

- G. Catalytic Cycle

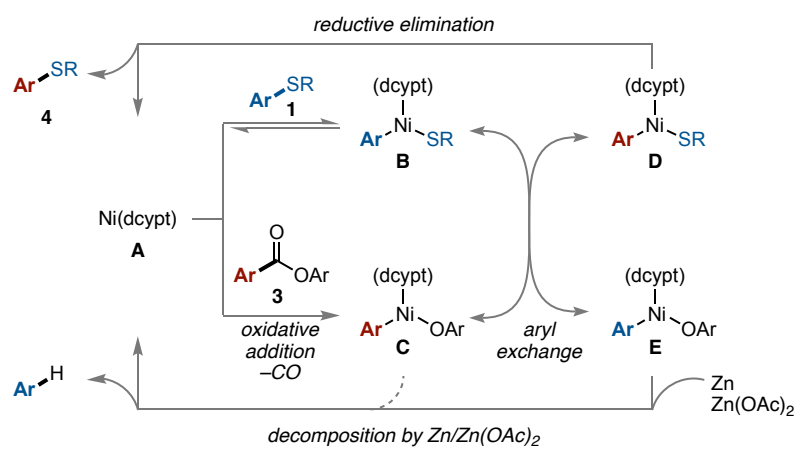

Figure 2. Mechanistic studies. (A) Oxidative addition of 6A. (B) Double oxidative addition of 6A and 3b and its time-course plot. (C) Reversibility of the $\mathrm{C}-\mathrm{S}$ bond oxidative addition and reductive elimination. (D) Reaction of nickel complexes 7 with 8. (E and F) Effect of $\mathrm{Zn}$ and $\mathrm{Zn}(\mathrm{OAc}) 2$. (G) A plausible catalytic cycle.

Combining the results from these mechanistic studies, a postulated catalytic cycle is illustrated in Figure $2 \mathrm{G}$. The Ni(0)dcypt complex can undergo two separate oxidative addition pathways, onto aryl sulfide $\mathbf{1}$ and onto aromatic ester $\mathbf{3}$, to generate aryl-NiSR species B and aryl-Ni-arenoxo species C, respectively. These complexes can react with each other, namely an exchange reaction, to give $\mathbf{D}$ and $\mathbf{E}$. The reductive elimination of $\mathbf{D}$ can furnish arylexchanged product 4 . On the other hands, intermediate $\mathbf{E}$ can be decomposed by $\mathrm{Zn}$ and $\mathrm{Zn}(\mathrm{OAc})_{2}$ to afford an arene and regenerate $\mathrm{Ni}(0)$ species $\mathbf{A}$. In this catalytic cycle, all of the steps except for the decomposition of $\mathbf{E}$ (and $\mathbf{C}$ ) are thought to be reversible.

These mechanistic studies informed us that the $\mathrm{Ni}(0)$ regeneration step from intermediate $\mathbf{E}$ would be a turnover-limiting step. Although $\mathrm{Zn}$ and $\mathrm{Zn}(\mathrm{OAc})_{2}$ enhanced this process, these zinc reagents also effected the undesired decomposition of $\mathrm{Ni}$-arenoxo intermediate C. Probably due to this difficulty, the substrate generality of this reaction turned out to be narrow (Scheme 1). For instance, the reactions of electron-rich (3c) as well as electrondeficient (3d) aromatic esters with $\mathbf{1 A}$ gave the corresponding aryl sulfides 4 in low yields. Even when we changed sulfide donor $\mathbf{1 A}$ to electron-deficient $\mathbf{6 A}$, the yield of $4 \mathrm{Ae}$ did not improve. In order to solve this issue, we sought an alternative protocol capable of accelerating the turnover-limiting decomposition of $\mathbf{E}$ selectively.

Scheme 1. Substrate Scope of the Reaction Using 1A and 6A.
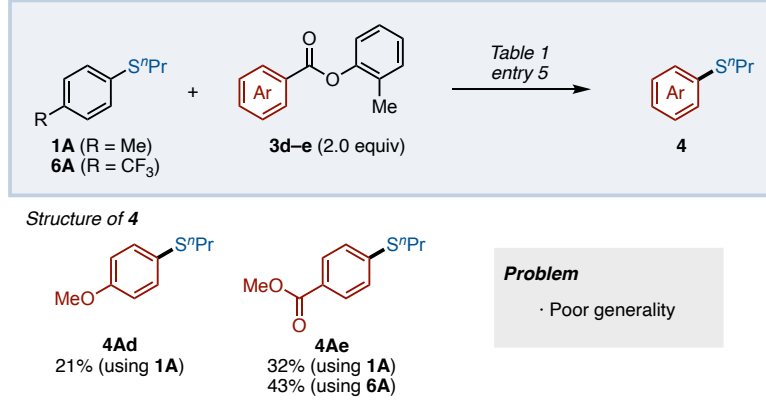

Poor generality $3 \%$ (using $6 A$ ) 
Conditions: $1 \mathrm{~A}$ or $6 \mathrm{~A}(0.20 \mathrm{mmol}), 3$ (2.0 equiv), $\mathrm{Ni}(\mathrm{OAc})_{2}(10$ $\mathrm{mol} \%)$, dcypt (15 mol \%), Zn (60 mol \%), Zn(OAc) 2 (50 mol \%), $\mathrm{Na}_{3} \mathrm{PO}_{4}$ (2.0 equiv), toluene $(0.80 \mathrm{~mL}), 150{ }^{\circ} \mathrm{C}, 24 \mathrm{~h}$.

To this end, we focused on employing 2-pyridyl sulfide as a sulfide donor (Figure 3A). We previously developed a decarbonylative synthesis of diarylethers, where we found that only the reductive elimination of 2-azinyl-O bonds from a Ni/dcypt complex was facile, but that of other aryl-O bonds is difficult. ${ }^{17,18}$ Accordingly, the use of 2-pyridyl sulfide can "funnel" this reversible catalytic cycle into desired products 4 by the selective enhancement of the reductive elimination of intermediate $\mathbf{E}$. To support this funneling strategy, we first subjected 2-pyridyl sulfide $1 \mathbf{1} \mathbf{A}$ with aromatic ester $\mathbf{3 b}$ to the aryl exchange reaction by using $\mathrm{Ni}(\operatorname{cod})_{2} / \mathrm{dcypt}$ in toluene at $150^{\circ} \mathrm{C}$ (Figure 3B). Delightfully, the reaction furnished aryl sulfide $\mathbf{4 A b}$ in $48 \%$ yield together with decarbonylative etherification product 12 in $53 \%$ yield. The reverse reaction was also conducted, generating only a tiny amount of $11 \mathrm{~A}$. This suggested that the reaction is no longer reversible with $11 \mathrm{~A}$. In contrast, when $1 \mathrm{~A}$ was subjected to these conditions instead of $11 \mathrm{~A}$, we confirmed that the reaction was completely reversible (See the SI for detail).

A. Expected role of 2-pyridyl thioether

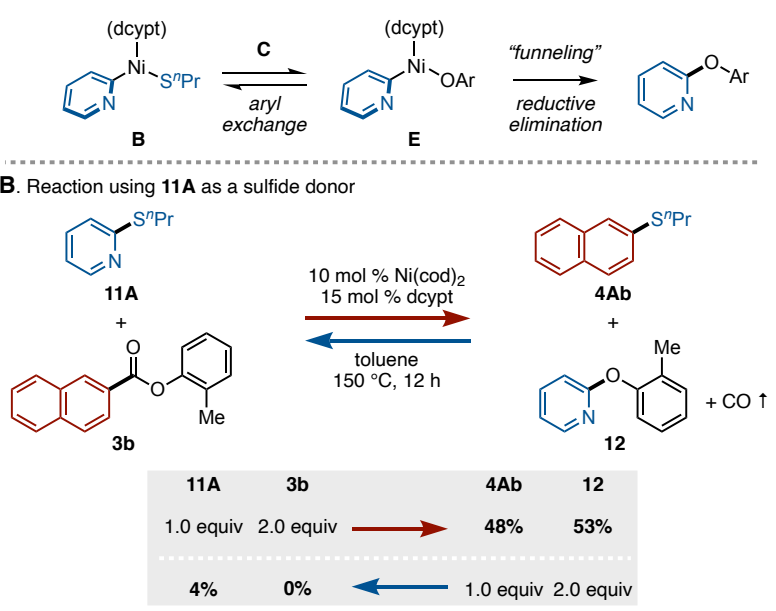

Figure 3. (A) 2-Pyridyl sulfide for a funneling strategy. (B) Forward reaction and reverse reaction of $11 \mathrm{~A}$.

Encouraged by this result, we optimized the reaction conditions by using $11 \mathbf{A}$ and $\mathbf{3 d}$ (Table 2 ). The use of $\mathrm{Ni}(\operatorname{cod})_{2} / \mathrm{dcypt}$ afforded 4Ad in $23 \%$ yield and 12 in $20 \%$ yield (Table 2, entry 1). When 11A was used as a sulfide donor, the addition of $\mathrm{Zn}(\mathrm{OAc})_{2}$ and $\mathrm{Na}_{3} \mathrm{PO}_{4}$ was not effective, but the addition of only $\mathrm{Zn}$ improved the yields of 4Ad and 12 (Table 2, entries 2-4). Increasing the amount of $\mathrm{Zn}$ slightly improved the yield (Table 2 , entry 5 ). Finally, a longer reaction time gave the best result (Table 2, entry 6).

Table 2. Optimization of Reaction Conditions Using 11A.

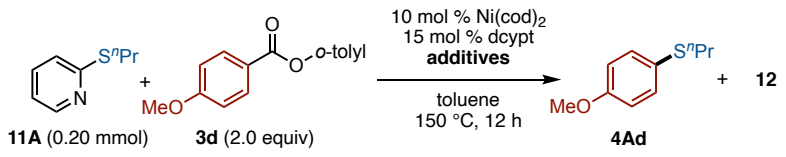

$\begin{array}{lcccll}\text { entry } & \mathrm{Zn} & \mathrm{Zn}(\mathrm{OAc})_{2} & \mathrm{Na}_{3} \mathrm{PO}_{4} & \text { Yield of } & \text { Yield of } \\ & 60 \mathrm{~mol} \% & 50 \mathrm{~mol} \% & 2.0 \text { equiv } & \text { 4Ad/\% } & 12 / \%^{a} \\ 1 & - & - & - & 23 & 20 \\ 2 & \circ & \circ & \circ & 26 & 4 \\ 3 & \circ & - & \circ & 30 & 33 \\ 4 & \circ & - & - & 46 & 54 \\ 5 & \circ^{b} & - & - & 49 & 54 \\ 6^{c} & \circ^{b} & - & - & 66 & 81\end{array}$

Conditions: $11 \mathrm{~A}(0.20 \mathrm{mmol}), 3 \mathrm{~d}$ (2.0 equiv), $\mathrm{Ni}(\mathrm{cod})_{2}(10 \mathrm{~mol} \%)$, dcypt $(15 \mathrm{~mol} \%)$, toluene $(0.80 \mathrm{~mL}), 150{ }^{\circ} \mathrm{C}, 12 \mathrm{~h} .{ }^{a}$ Determined by ${ }^{1} \mathrm{H}$ NMR analysis. ${ }^{b} \mathrm{Zn}$ (1.0 equiv). ${ }^{c} 24 \mathrm{~h}$.

With the optimized conditions in hand, we then evaluated the substrate scope of the present reaction (Scheme 2). First, we examined the scope of sulfide groups. This reaction successfully transferred primary, secondary, and tertiary alkyl sulfide groups to give the corresponding aryl sulfides in moderate yields $(\mathbf{4 B b}, \mathbf{4 C b}$, $\mathbf{4 D b}$ ). Of note, for the methyl sulfide $\mathbf{4 B b}$ synthesis, the present method is more advantageous than typical cross-coupling methods using methane thiol, because methane thiol is a gaseous (b.p. $=6^{\circ} \mathrm{C}$ ) and strongly odorous reagent, often associated with cumbersome handling. Other alkyl sulfides bearing $\mathrm{CF}_{3}(\mathbf{4 E b})$, cyclobutyl (4Fb, $\mathbf{4 F f})$, and arenes $(\mathbf{4 G b})$ were synthesized in acceptable yields. Nitrogen substituents on sulfide groups were compatible with the present reaction $(\mathbf{4 H b}, 4 \mathrm{Ib}, 4 \mathrm{Ig})$. The scope of arenes was next investigated. It was revealed that para- and meta-substituents did not affect on this reaction significantly (4Aa, $4 \mathrm{Ah})$, however, orthosubstituents inhibited the reaction due to steric repulsions with the catalyst (4Ai). With respect to the electronic nature of substituents, both electron-donating and electron-withdrawing groups at the para-position were applicable to the present reaction. Aryl sulfides bearing methyl (4Aj), methoxy (4Ad), phenoxy (4Ak) and dioxole (4Al) were obtained in moderate yields. Compared to Morandi's recent method that was mainly effective for the synthesis of aryl sulfides with electron-withdrawing groups, ${ }^{14}$ it is noteworthy that our present reaction can also synthesize highly electron-rich arenes such as methoxy and phenoxy aryl sulfides (4Ad, 4Ak). Several electron-withdrawing groups including highly reactive functional groups such as alkyl ester (4Ae), cyano (4An), ketone (4Ao), and amide (4Ap) were tolerated. Naphthyl sulfides (4Ab, $4 A q)$ were obtained in good to moderate yields. The exchange reaction of heteroaromatic esters was also viable to this reaction, furnishing the corresponding heteroaryl sulfides in moderate yields ( $4 \mathrm{Ff}, 4 \mathrm{Ar}, 4 \mathrm{As}$, 4At).

Scheme 2. Substrate Scope of the Reaction Using 11. ${ }^{a}$ 


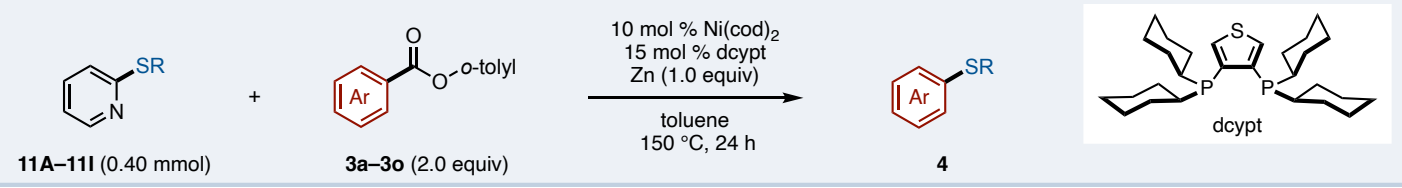

structure of products

- sulfides
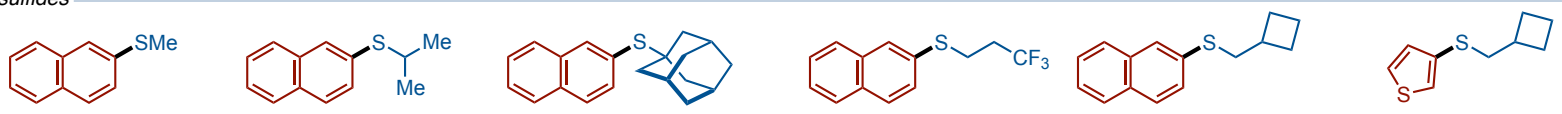

4Bb: $43 \%$

4Cb: $56 \%$

4Db: $65 \%$

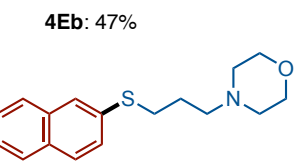

4lb: $48 \%$

4Fb: $62 \%$

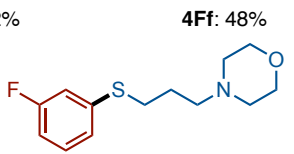

4lg: $53 \%$

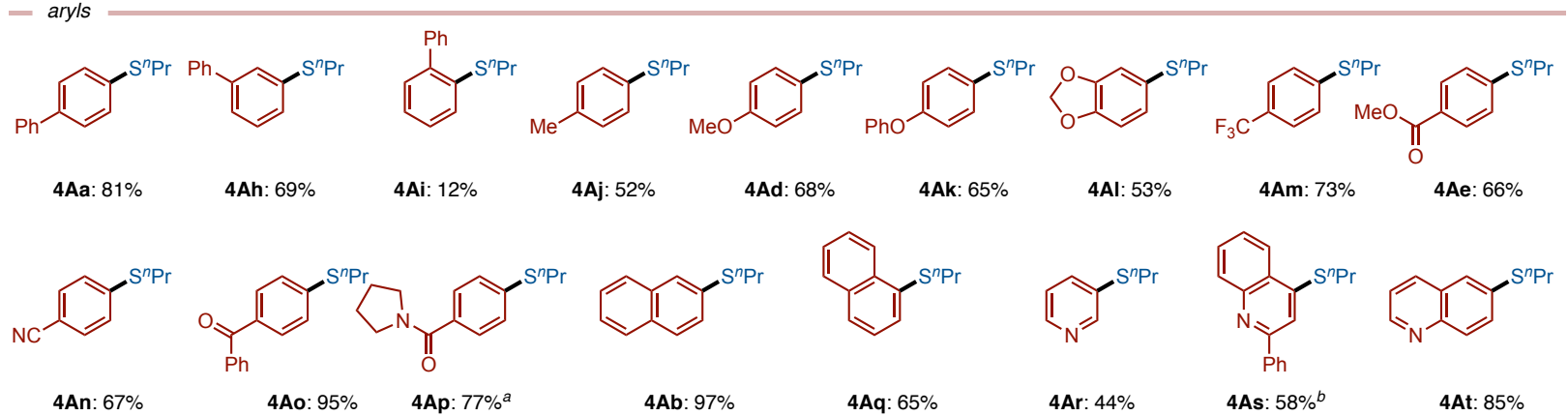

Conditions: $11(0.40 \mathrm{mmol}), 3$ (2.0 equiv), Ni(cod) $2(10 \mathrm{~mol} \%)$, dcypt $(15 \mathrm{~mol} \%), \mathrm{Zn}\left(1.0\right.$ equiv), toluene $(1.6 \mathrm{~mL}), 150{ }^{\circ} \mathrm{C}, 24 \mathrm{~h} . \mathrm{Yields}$ of isolated products are shown. ${ }^{a}$ Obtained as a sulfone after oxidation by $m \mathrm{CPBA} .{ }^{b}$ Obtained as a sulfoxide after oxidation by Oxone.

We then performed this reaction in an intramolecular setting. Pyridine 13 bearing both a sulfide and a tolylester was treated under the optimized conditions (Scheme 3A). As a result, we obtained 2arenoxylated 3-pyridyl sulfide 14 in 35\% yield. This transformation proceeds through a double exchange reaction on the pyridine ring, which is rare in other exchange reactions. ${ }^{10} \mathrm{Next}$, we expected that thioester $\mathbf{1 5}$ can be used as a sulfide donor through our previously developed $\mathrm{Ni}$-catalyzed decarbonylation ${ }^{5 \mathrm{e}}$ to form 2-pyridyl sulfide in-situ (Scheme 3B). Delightfully, under the $\mathrm{Ni} / \mathrm{dcypt}$ catalysis, we obtained aryl sulfide product 16 in $62 \%$ yield along with 2 arenoxypyridine 12 in $69 \%$ yield.

Scheme 3. (A) An Intramolecular Reaction of 13 (B) A Reaction Using Thioester 15.

A.

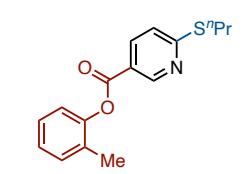

$10 \mathrm{~mol} \% \mathrm{Ni}(\mathrm{cod})_{2}$

$15 \mathrm{~mol} \%$ dcypt
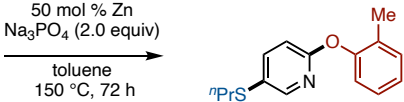

$13(0.15 \mathrm{mmol})$

$14: 35 \%$

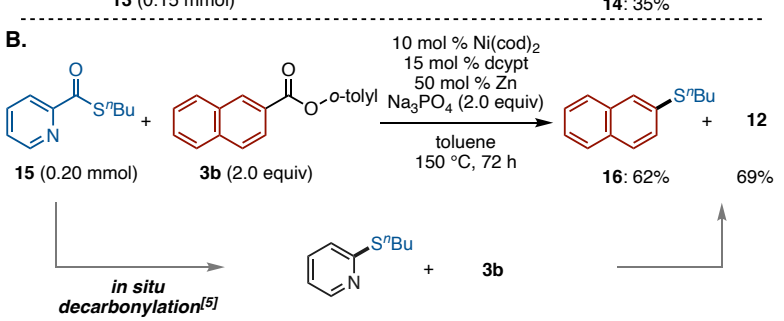

Because $\mathrm{Ni} /$ dcypt catalyst is known to be effective for the oxidative addition of aryl halides as well as arenol derivatives, we thought that it is possible to utilize other aryl electrophiles than aromatic esters (Scheme 4). ${ }^{12}$ Delightfully, Ni/dcypt/Zn catalysis was found to be applicable to aryl pivalate, carbamate, carbonate, sulfonate, bromide, and chlorides, giving a desired aryl sulfide $\mathbf{4 A b}$ in generally good yields. We evaluated the substrate generality of the reaction using aryl pivalates 17 and aryl carbamates 18. Pivalates 17 bearing both electron-donating groups $(17 \mathbf{j}, 17 \mathbf{u}, 17 \mathbf{v})$ and phenyl (17h) engaged in this reaction to give the corresponding aryl sulfides. Sensitive functional groups such as esters $(\mathbf{1 7 e})$, ketones $(17 w$ and $17 x)$, secondary amides $(17 y)$, and boronic esters $(17 z)$ were tolerated. Pyridyl (18r) and quinolinyl (18aa) carbamates were also suitable substrates, being converted to the corresponding aryl sulfides in good yields. Furthermore, naphthalene with both pivalate and aryl ester (17ab) was tested to examine which group reacts faster. As a result, aromatic ester 4Aab was obtained as a major product in 56\% yield (see the SI for details).

Scheme 4. Scope of Sulfide Acceptors 


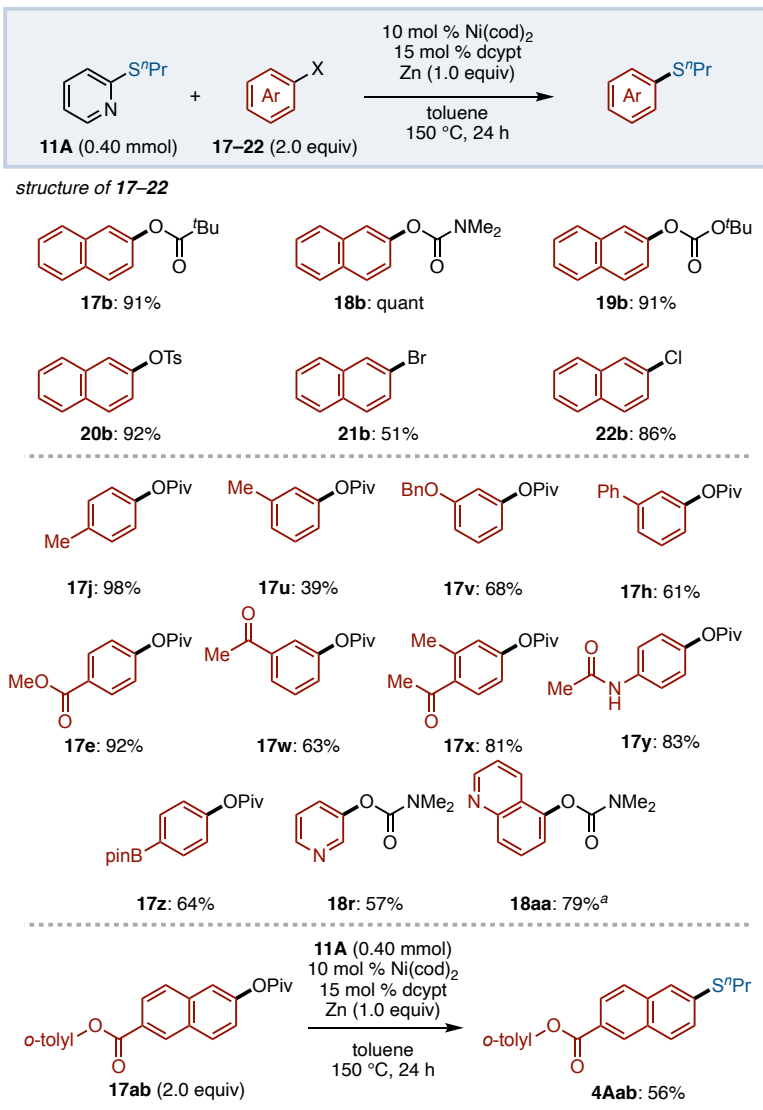

Conditions: 11A $(0.40 \mathrm{mmol}), \mathbf{1 7}-\mathbf{2 2}$ (2.0 equiv), $\mathrm{Ni}(\operatorname{cod})_{2}(10$ $\mathrm{mol} \%)$, dcypt (15 mol \%), $\mathrm{Zn}$ (1.0 equiv), toluene $(1.6 \mathrm{~mL}), 150^{\circ} \mathrm{C}, 24$ h. Yields of isolated products are shown. ${ }^{a}$ Obtained as a sulfone after oxidation by $m \mathrm{CPBA}$.

Aromatic esters, arenols, and aryl halides are frequently seen in natural products and pharmaceuticals. Expecting that the present method can be applied to a late-stage $\mathrm{C}-\mathrm{S}$ bond formation via functional group interconversion, we performed reactions on known substrates with many functional groups. ${ }^{19}$ As a result, we succeeded in derivatizing biologically active molecules such as probenecid aryl ester, flavone, estrone, phenylalanine, umbelliferone, and $\beta$ isocupreidine pivalates in good yields (Scheme 5). Drug molecules containing an aryl chloride moiety were also transformed into the corresponding aryl sulfides in good yields. Of note, in these demonstrations, it was shown that the present method was compatible with reactive functional groups such as ketones, imides, esters, tertiary amines, and tertiary alcohol groups.

Scheme 5. Late-Stage C-S Bond Formation via Functional Group Interconversion.

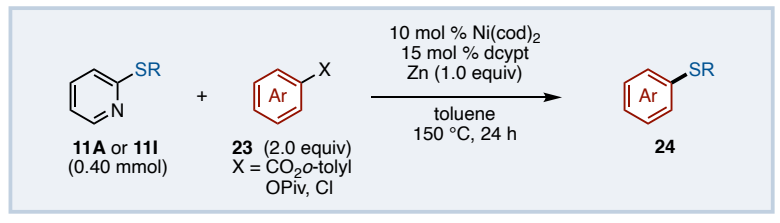

structure of 24
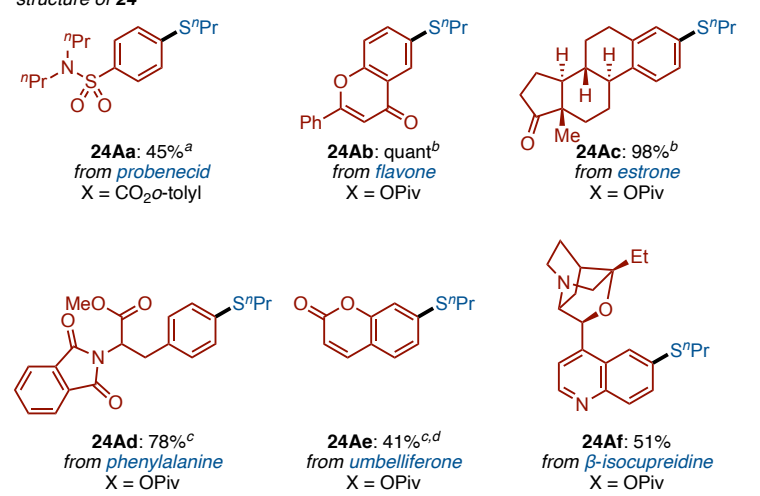

24Af: $51 \%$ $\beta$-isocupreidine
$\mathrm{X}=\mathrm{OPiv}$
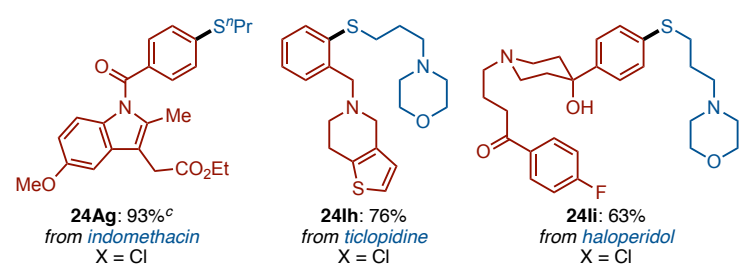

Conditions: 11 ( $0.40 \mathrm{mmol}), 23$ (2.0 equiv), $\mathrm{Ni}(\operatorname{cod})_{2}(10 \mathrm{~mol} \%)$, dcypt ( $15 \mathrm{~mol} \%), \mathrm{Zn}$ (1.0 equiv), toluene $(1.6 \mathrm{~mL}), 150^{\circ} \mathrm{C}, 24 \mathrm{~h}$. Yields of isolated products are shown. ${ }^{a}$ Obtained as a sulfone after oxidation by Oxone ${ }^{\otimes} .{ }^{b}$ Obtained as a sulfoxide after oxidation by $m$ CPBA. ${ }^{c}$ Obtained as a sulfone after oxidation by $m \mathrm{CPBA} .{ }^{d} \mathrm{Ni}(\mathrm{OAc})_{2}(10 \mathrm{~mol} \%)$, dcypt (15 mol \%), $\mathrm{Na}_{3} \mathrm{PO}_{4}$ (2.0 equiv), $\mathrm{Zn}$ (60 mol \%), $\mathrm{Zn}(\mathrm{OAc})_{2}(50 \mathrm{~mol} \%)$.

In summary, we have developed a $\mathrm{Ni}$-catalyzed aryl sulfide synthesis through an aryl exchange. By using 2-pyridyl sulfide as a sulfide donor, not only aromatic esters, but also arenols and haloarenes can be used as a sulfide acceptor. This method presents a new aryl sulfide synthesis without using highly nucleophilic and odorous thiols. Mechanistic studies confirmed that this reaction proceeded through two oxidative additions of aryl sulfides and aromatic esters at the same time, followed by exchange reaction between the resulting nickel complexes. Further studies to develop other aryl exchange reactions and detailed mechanistic studies in detail are ongoing in our laboratory. ${ }^{20}$

\section{ASSOCIATED CONTENT}

\section{Supporting Information}

The Supporting Information is available free of charge.

Experimental procedures and spectroscopic data for compounds including ${ }^{1} \mathrm{H}-{ }^{13} \mathrm{C}-,{ }^{19} \mathrm{~F}-$, and ${ }^{31} \mathrm{P}$ NMR spectra and crystallographic data (PDF). CCDC 2074846 contains the supplementary crystallographic data for this paper.

\section{AUTHOR INFORMATION}

\section{Corresponding Author}

*junyamaguchi@waseda.jp

\section{ORCID}

Ryota Isshiki: 0000-0002-5043-3694 
Kei Muto: 0000-0001-8301-4384

Junichiro Yamaguchi: 0000-0002-3896-5882

Notes

The authors declare no competing financial interest.

\section{ACKNOWLEDGMENT}

This work was supported by JSPS KAKENHI Grant Number JP JP19H02726 (to J.Y.), JP19K15573, JP20H04829 (hybrid catalysis) (to K.M.), JP19J23053 and Waseda Research Institute for Science and Engineering, Grant in Aid for Young Scientists (Early Bird) (to R.I.). This work was also partly supported by JST ERATO Grant Number JPMJER1901 (to J.Y.). We thank Dr. Kenta Kato (Waseda University) for assistance with X-ray crystallographic analysis. We also thank the National Institute of Health Sciences in Japan for the support of NMR measurement. The Materials Characterization Central Laboratory in Waseda University is acknowledged for the support of HRMS measurement.

\section{REFERENCES}

(1) (a) Dunbar, K. L.; Scharf, D. H.; Litomska, A.; Hertweck, C. Enzymatic Carbon-Sulfur Bond Formation in Natural Product Biosynthesis. Chem. Rev. 2017, 117, 5521-5577. (b) Ilardi, E. A.; Vitaku, E.; Njardarson, J. T. Data-Mining for Sulfur and Fluorine: An Evaluation of Pharmaceuticals to Reveal Opportunities for Drug Design and Discovery. J. Med. Chem. 2014, 57, 2832-2842. (c) Zhao, C.; Rakesh, K. P.; Ravidar, L.; Fang, W.-Y.; Qin, H.-L. Pharmaceutical and Medicinal Significance of Sulfur $\left(S^{\text {VI }}\right)$ Containing Motifs for Drug Discovery: A Critical Review. Eur. J. Med. Chem. 2019, 162, 679-734.

(2) For selected reviews of C-S bond formation, see: (a) Kondo, T.; Mitsudo, T. Metal-Catalyzed Carbon-Sulfur Bond Formation. Chem. Rev. 2000, 100, 3205-3220. (b) Ley, S. V.; Thomas, A. W. Modern Synthetic Methods for Copper-Mediated C(aryl)-O, C(aryl)-N, and C(aryl)-S Bond Formation. Angew. Chem., Int. Ed. 2003, 42, 5400-5449. (c) Beletskaya, I. P.; Ananikov, V. P. Transition-Metal-Catalyzed C-S, C-Se, and $\mathrm{C}-\mathrm{Te}$ Bond Formation via Cross-Coupling and Atom-Economic Addition Reactions. Chem. Rev. 2011, 111, 1596-1636.

(3) For representative examples of $\mathrm{C}-\mathrm{S}$ bond forming cross-coupling, see: (a) Kosugi, M.; Shimizu, T.; Migita, T. Reactions of Aryl Halides with Thiolate Anions in the Presence of Catalytic Amounts of Tetrakis(Triphenylphosphine)Palladium Preparation of Aryl Sulfides. Chem. Lett. 1978, 7, 13-14. (b) Murata, M.; Buchwald, S. L. A General and Efficient Method for the Palladium-Catalyzed Cross-Coupling of Thiols and Secondary Phosphines. Tetrahedron 2004, 60, 7397-7403. (c) FernándezRodríguez, M. A.; Shen, Q.; Hartwig, J. F. A General and Long-Lived Catalyst for the Palladium-Catalyzed Coupling of Aryl Halides with Thiols. J. Am. Chem. Soc. 2006, 128, 2180-2181. (d) Sayah, M.; Organ, M. G. Carbon-Sulfur Bond Formation of Challenging Substrates at Low Temperature by Using Pd-PEPPSI-IPent. Chem. Eur. J. 2011, 17, 1171911722. (e) Kwong, F. Y.; Buchwald, S. L. A General, Efficient, and Inexpensive Catalyst System for the Coupling of Aryl Iodides and Thiols. Org. Lett. 2002, 4, 3517-3520. (f) Liu, B.; Lim, C.-H.; Miyake, G. M. Visible-Light-Promoted C-S Cross-Coupling via Intermolecular Charge Transfer. J. Am. Chem. Soc. 2017, 139, 13616-13619. (g) Wang, X.; Cuny, G. D.; Noël, T. A Mild, One-Pot Stadler-Ziegler Synthesis of Arylsulfides Facilitated by Photoredox Catalysis in Batch and Continuous-Flow. Angew. Chem., Int. Ed. 2013, 52, 7860-7864. (h) Uyeda, C.; Tan, Y.; Fu, G. C.; Peters, J. C. A New Family of Nucleophiles for Photoinduced, CopperCatalyzed Cross-Couplings via Single-Electron Transfer: Reactions of Thiols with Aryl Halides Under Mild Conditions $\left(0^{\circ} \mathrm{C}\right)$. J. Am. Chem. Soc. 2013, 135, 9548-9552. (g) Yin, G.; Kalvet, I.; Englert, U.; Schoenebeck, F. Fundamental Studies and Development of Nickel-Catalyzed Trifluoromethylthiolation of Aryl Chlorides: Active Catalytic Species and Key Roles of Ligand and Traceless MeCN Additive Revealed. J. Am. Chem. Soc. 2015, 137, 4164-4172. (h) Oderinde, M. S.; Frenette, M.; Robbins, D. W.; Aquila, B.; Johannes, J. W. Photoredox Mediated Nickel Catalyzed
Cross-Coupling of Thiols with Aryl and Heteroaryl Iodides via Thiyl Radicals. J. Am. Chem. Soc. 2016, 138, 1760-1763.

(4) (a) Taniguchi, N. Alkyl- or Arylthiolation of Aryl Iodide via Cleavage of the S-S Bond of Disulfide Compound by Nickel Catalyst and Zinc. J. Org. Chem. 2004, 69, 6904-6906. (b) Taniguchi, N.; Onami, T. MagnesiumInduced Copper-Catalyzed Synthesis of Unsymmetrical Diaryl Chalcogenide Compounds from Aryl Iodide via Cleavage of the Se-Se or SS Bond. J. Org. Chem. 2004, 69, 915-920.

(5) (a) Osakada, K.; Yamamoto, T.; Yamamoto, A. "Decarbonylation of Thiol Esters to Give Sulfides Promoted by Transition Metal Complexes" Tetrahedron Lett. 1987, 28, 6321-6324. (b) Ichiishi, N.; Malapit, C. A.; Woźniak, Ł.; Sanford, M. S. Palladium- and Nickel-Catalyzed Decarbonylative C-S Coupling to Convert Thioesters to Thioethers. Org. Lett. 2018, 20, 44-47. (c) Lee, S.-C.; Liao, H.-H.; Chatupheeraphat, A.; Rueping, M. Nickel-Catalyzed C-S Bond Formation via Decarbonylative Thioetherification of Esters, Amides and Intramolecular Recombination Fragment Coupling of Thioesters. Chem. Eur.J. 2018, 24, 3608-3612. (d) Liu, C.; Szostak, M. Decarbonylative Thioetherification by Nickel Catalysis using Air- and Moisture-stable Nickel Precatalysts. Chem. Commun. 2018, 54, 2130-2133. (e) Ishitobi, K.; Isshiki, R.; Asahara, K. K.; Lim, C.; Muto, K.; Yamaguchi, J. Decarbonylative Aryl Thioether Synthesis by Ni Catalysis. Chem. Lett. 2018, 47, 756-759.

(6) (a) Mao, J.; Jia, T.; Frensch, G.; Walsh, P. J. Palladium-Catalyzed Debenzylative Cross-Coupling of Aryl Benzyl Sulfides with Aryl Bromides: Synthesis of Diaryl Sulfides. Org. Lett. 2014, 16, 5304-5307. (b) Li, Y.; Bao, G.; Wu, X.-F. Palladium-Catalyzed Intermolecular Transthioetherification of Aryl Halides with Thioethers and Thioesters. Chem. Sci. 2020, 11, $2187-$ 2192.

(7) Cham-Lam-Evans type aryl sulfide synthesis using arylboronic acids with sulfur imides were also reported. Savarin, C.; Srogl, J.; Liebeskind, L. S. A Mild, Nonbasic Synthesis of Thioethers. The Copper-Catalyzed Coupling of Boronic Acids with $\mathrm{N}$-Thio(alkyl, aryl, heteroaryl)imides. Org. Lett. 2002 4, 4309-4312.

(8) For reviews on a functional group transfer reaction, see: (a) Bhawal, B. N.; Morandi, B. Catalytic Isofunctional Reactions-Expanding the Repertoire of Shuttle and Metathesis Reactions. Angew. Chem., Int. Ed. 2019, 58, 10074-10103. (b) Boehm, P.; Morandi, B. New Catalysis Concepts for Molecular Design and Feedstocks Valorization. CHIMIA 2020, 74, 724-729.

(9) Conceptually similar transfer reactions were also known. (a) Jun, C.H.; Lee, H. Catalytic Carbon-Carbon Bond Activation of Unstrained Ketone by Soluble Transition-Metal Complex. J. Am. Chem. Soc. 1999, 121, 880-881. (b) Arisawa, M.; Igarashi, Y.; Kobayashi, H.; Yamada, T.; Bando, K.; Ichikawa, T.; Yamaguchi, M. Equilibrium Shift in the RhodiumCatalyzed Acyl Transfer Reactions. Tetrahedron 2011, 67, 7846-7859. (c) Murphy, S. K.; Park, J.-W.; Cruz, F.A.; Dong, V. M. Rh-Catalyzed C-C Bond Cleavage by Transfer Hydroformylation. Science 2015, 347, 56-60. (d) Fang, X.; Yu, P.; Morandi, B. Catalytic Reversible Alkene-Nitrile Interconversion Through Controllable Transfer Hydrocyanation. Science 2016, 351, 832-836. (e) Fan, C.; Lv, X.-Y.; Xiao, L.-J.; Xie, J.-H.; Zhou, Q.L. Alkenyl Exchange of Allylamines via Nickel(0)-Catalyzed C-C Bond Cleavage. J. Am. Chem. Soc. 2019, 141, 2889-2893. (f) Kanda, T.; Naraoka, A.; Naka, H. Catalytic Transfer Hydration of Cyanohydrins to $\alpha$ Hydroxyamides. J. Am. Chem. Soc. 2019, 141, 825-830.

(10) (a) Lee, Y. H.; Morandi, B. Metathesis-Active Ligands Enable a Catalytic Functional Group Metathesis Between Aroyl Chlorides and Aryl Iodides. Nat. Chem. 2018, 10, 1016-1022. (b) De La Higuera Macias, M.; Arndtsen, B. A. Functional Group Transposition: A Palladium-Catalyzed Metathesis of Ar-X $\sigma$-Bonds and Acid Chloride Synthesis. J. Am. Chem. Soc. 2018, 140, 10140-10144.

(11) Isshiki, R.; Inayama, N.; Muto, K.; Yamaguchi, J. Ester Transfer Reaction of Aromatic Esters with Haloarenes and Arenols by a Nickel Catalyst. ACS Catal. 2020, 10, 3490-3494.

(12) For examples of $\mathrm{Ni} / \mathrm{dcypt}$-catalyzed reaction involving the cleavage of inert bonds, see: (a) Takise, R.; Muto, K.; Yamaguchi, J.; Itami, K. NickelCatalyzed $\alpha$-Arylation of Ketones with Phenol Derivatives. Angew. Chem., Int. Ed. 2014, 53, 6791-6794. (b) Koch, E.; Takise, R.; Studer, A.; Yamaguchi, J.; Itami, K. Ni-Catalyzed $\alpha$-Arylation of Esters and Amides with 
Phenol Derivatives. Chem. Commun. 2015, 51, 855-857. (c) Takise, R.; Itami, K.; Yamaguchi, J. Cyanation of Phenol Derivatives with Aminoacetonitriles by Nickel Catalysis. Org. Lett. 2016, 18, 4428-4431. (d) Muto, K.; Hatakeyama, T.; Yamaguchi, J.; Itami, K. C-H Arylation and Alkenylation of Imidazoles by Nickel Catalysis: Solvent-Accelerated Imidazole C-H Activation. Chem. Sci. 2015, 6, 6792-6798. (e) Isshiki, R.; Muto, K.; Yamaguchi, J. Decarbonylative C-P Bond Formation Using Aromatic Esters and Organophosphorus Compounds. Org. Lett. 2018, 20, 1150-1153. (f) Okita, T.; Muto, K.; Yamaguchi, J. Decarbonylative Methylation of Aromatic Esters by a Nickel Catalyst. Org. Lett. 2018, 20, 3132-3135. (g) Iizumi, K.; Kurosawa, M. B.; Isshiki, R.; Muto, K.; Yamaguchi, J. Decarbonylative Synthesis of Aryl Nitriles from Aromatic Esters and Organocyanides by a Nickel Catalyst. Synlett 2020, eFirst. DOI: 10.1055/s-0040-1705943.

(13) (a) Mann, G.; Baranano, D.; Hartwig, J. F.; Rheingold, A. L.; Guzei, I. A. Carbon-Sulfur Bond-Forming Reductive Elimination Involving sp-, $\mathrm{sp}^{2}$-, and $\mathrm{sp}^{3}$-Hybridized Carbon. Mechanism, Steric Effects, and Electronic Effect on Sulfide Formation. J. Am. Chem. Soc. 1998, 120, 9205-9219. (b) Alvaro, E.; Hartwig, J. F. Resting State and Elementary Steps of the Coupling of Aryl Halides with Thiols Catalyzed by Alkylbisphosphine Complexes of Palladium. J. Am. Chem. Soc. 2009, 131, 7858-7868.

(14) During the preparation of this manuscript, the Morandi group elegantly developed complete aryl exchange reaction between aryl nitriles with aryl sulfide using Ni/dcype catalyst. Delcaillau, T.; Boehm, P.; Morandi, B. Nickel-Catalyzed Reversible Functional Group Metathesis between Aryl Nitriles and Aryl Thioethers. J. Am. Chem. Soc. 2021, 143, 3723-3728.

(15) For reductive biaryl couplings using $\mathrm{Ni} / \mathrm{Zn}$ catalysis, see: (a) Ackerman, L. K. G.; Lovell, M. M.; Weix, D. J. Multimetallic Catalysed Cross-Coupling of Aryl Bromides with Aryl Triflates. Nature 2015, 524, 454-457. (b) Huang, L.; Ackerman, L. K. G.; Kang, K.; Parsons, A. M.; Weix, D. J. LiCl-Accelerated Multimetallic Cross-Coupling of Aryl Chlorides with Aryl Triflates. J. Am. Chem. Soc. 2019, 141, 10978-10983. (c) Kang, K.; Huang, L.; Weix, D. J. Sulfonate versus Sulfonate: Nickel and Palladium Multimetallic Cross-Electrophile Coupling of Aryl Triflates with Aryl Tosylates. J. Am. Chem. Soc. 2020, 142, 10634-10640.

(16) For reviews of catalytic reactions through $\mathrm{C}(\operatorname{aryl})-\mathrm{S}$ bond oxidative addition, see: (a) Dubbaka, S. R.; Vogel, P. Organosulfur Compounds: Electrophilic Reagents in Transition-Metal-Catalyzed Carbon-Carbon Bond-Forming Reactions. Angew. Chem., Int. Ed. 2005, 44, 7674-7684. (b) Modha, S. G.; Mehta, V. P.; Van der Eycken, E. V. Transition MetalCatalyzed C-C Bond Formation via $\mathrm{C}-\mathrm{S}$ Bond Cleavage: An Overview. Chem. Soc. Rev. 2013, 42, 5042-5055. (c) Wang, L.; He, W.; Yu, Z.
Transition-Metal Mediated Carbon-Sulfur Bond Activation and Transformations. Chem. Soc. Rev. 2013, 42, 599-621. For selected examples, see: (d) Barbero, N.; Martin, R. Ligand-Free Ni-Catalyzed Reductive Cleavage of Inert Carbon-Sulfur Bonds. Org. Lett. 2012, 14, 796-799. (e) Sugahara, T.; Murakami, K.; Yorimitsu, H.; Osuka, A Palladium-Catalyzed Amination of Aryl Sulfides with Anilines. Angew. Chem., Int. Ed. 2014, 53, 9329-9333. (f) Tobisu, M.; Masuya, Y.; Baba, K.; Chatani, N. Palladium(ii)-Catalyzed Synthesis of Dibenzothiophene Derivatives via the Cleavage of Carbon-Sulfur and Carbon-Hydrogen Bonds. Chem. Sci. 2016, 7, 2587-2591. (g) Ma, Y.; Cammarata, J.; Cornella, J. Ni-Catalyzed Reductive Liebeskind-Srogl Alkylation of Heterocycles. J. Am. Chem. Soc. 2019, 141, 1918-1922. (h) Lian, Z.; Bhawal, B. N.; Yu, P.; Morandi, B. Palladium-Catalyzed Carbon-Sulfur or Carbon-Phosphorus Bond Metathesis by Reversible Arylation. Science 2017, 356, 1059-1063. (i) Delcaillau, T.; Bismuto, A.; Lian Z.; Morandi, B. Nickel-Catalyzed Interand Intramolecular Aryl Thioether Metathesis by Reversible Arylation. Angew. Chem., Int. Ed. 2020, 59, 2110-2114. (j) Bismuto, A.; Delcaillau, T.; Müller, P.; Morandi, B. Nickel-Catalyzed Amination of Aryl Thioethers: A Combined Synthetic and Mechanistic Study. ACS Catal. 2020, 10, 46304639.

(17) Takise, R.; Isshiki, R.; Muto, K.; Itami, K.; Yamaguchi, J. Decarbonylative Diaryl Ether Synthesis by Pd and Ni Catalysis. J. Am. Chem. Soc. 2017, 139, 3340-3343.

(18) For selected reviews on catalytic decarbonylative transformation, see: (a) Takise, R.; Muto, K.; Yamaguchi, J. Cross-Coupling of Aromatic Esters and Amides. Chem. Soc. Rev. 2017, 46, 5864-5888. (b) Lu, H.; Yu, T.-Y.; Xu, P.-F.; Wei, H. Selective Decarbonylation via Transition-MetalCatalyzed Carbon-Carbon Bond Cleavage. Chem. Rev. 2021, 121, 365411.

(19) (a) Dominguez-Huerta, A.; Dai, X.-J.; Zhou, F.; Querard, P.; Qiu, Z.; Ung, S.; Liu, W.; Li, J.; Li, C.-J. Exploration of New Reaction Tools for Late-Stage Functionalization of Complex Chemicals. Can. J. Chem. 2019, 97,67-85. (b) Cannalire, R.; Pelliccia, S.; Sancineto, L.; Novellino, E.; Tron, G. C.; Giustiniano, M. Visible Light Photocatalysis in the Late-Stage Functionalization of Pharmaceutically Relevant Compounds. Chem. Soc. Rev. 2021, 50, 766-897. (c) Hong, B.; Luo, T.; Lei, X. Late-Stage Diversification of Natural Products. ACS Cent. Sci. 2020, 6, 622-635. (d) Cernak, T.; Dykstra, K. D.; Tyagarajan, S.; Vachal, P.; Krska, S. W. The Medicinal Chemist's Toolbox for Late Stage Functionalization of Drug-like Molecules. Chem. Soc. Rev. 2016, 45, 546-576. 


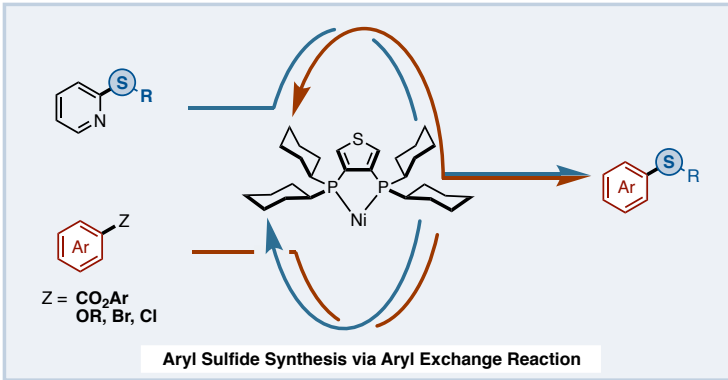

